Biol. Proced. Online 2003;5(1): 29-42.

\title{
Progressive Rearrangement of Telomeric Sequences Added to Both the ITR Ends of the Yeast Linear pGKL Plasmid
}

\author{
Norio Gunge $^{1 *}$, Hideki Takata ${ }^{2}$, Akira Matsuura $^{2}$, Kohsai Fukuda ${ }^{1}$ \\ ${ }^{1}$ Molecular Genetics, Applied Microbial Technology, Sojo University, Ikeda 4-22-1, Kumamoto, 860-0082, Japan \\ ${ }^{2}$ Department of Geriatric Research, National Institute for Longevity Sciences, Gengo 36-3, Morioka, Obu, 474-8522, Japan \\ *To whom correspondence should be addressed. Tel: 096-326-3111; Fax: 096-323-1330 E-mail: gunge@bio.sojo-u.ac.jp
}

Submitted: December 2, 2002; Revised: December 6, 2002; Accepted: January 15, 2003; Published: February 17, 2003

Indexing terms: linear pGKL plasmid, cytoplasmic linear plasmid, telomere de novo addition, telomerase, Kluyveromyces lactis, Saccharomyces cerevisiae.

\begin{abstract}
Relocation into the nucleus of the yeast cytoplasmic linear plasmids was studied using a monitor plasmid pCLU1. In Saccharomyces cerevisiae, the nuclearly-relocated pCLU1 replicated in a linear form (termed pTLU-type plasmid) which carried the host telomeric repeats $\mathrm{TG}_{1-3}$ of 300-350 bp at both ends. The telomere sequences mainly consisted of a major motif TGTGTGGGTGTGG which was complementary to part of the RNA template of yeast telomerase and were directly added to the very end of the pCLU1-terminal element ITR (inverted terminal repeat), suggesting that the ITR end played a role as a substrate of telomerase. The telomere sequences varied among isolated pTLU-type plasmids, but the $\mathrm{TG}_{1-3}$ organization was symmetrically identical on both ends of any one plasmid. During cell growth under non-selective condition, the telomeric repeat sequences were progressively rearranged on one side, but not on the opposite side of pTLU plasmid ends. This indicates that the mode of telomeric DNA replication or repair differed between both ends. Clonal analysis showed that the intense rearrangement of telomeric DNA was closely associated with extreme instability of pTLU plasmids.
\end{abstract}

\section{INTRODUCTION}

The Kluyveromyces linear plasmids, pGKL1 and pGKL2, have specialized terminal structure: inverted terminal repeats (ITRs) whose 5 'ends are covalently associated with terminal proteins (TPs). They replicate in the cytoplasm of yeast, either Saccharomyces cerevisiae or Kluyveromyces lactis, presumably using TP as a primer of DNA-replication similar to the adenovirus or bacteriophage $\phi 29$ genome (1-6). The pGKL plasmids have a unique transcription system which functions in the cytoplasm. All 15 genes (ORFs) on pGKL1 and pGKL2 are preceded by the specific promoter of their own, termed UCS (Upstream Consensus Sequence), with a motif ACT(A/T)ATNTGA (N, any base) $(4,6,7,8)$, which are directed by the pGKL2-encoded RNA polymerase. The mRNA-5'capping may also occur by an action of the pGKL2 gene (9). The pGKL gene expression system is different from the nuclear system. That is, the pGKL-genes are nonexpressible on conventional nuclear vectors of yeast $(7,10)$. Conversely, the nuclear or foreign genes (e.g. ScLEU2, $\mathrm{Sc} U R A 3, \mathrm{Km}^{\mathrm{R}}$, etc.) do not function on the cytoplasmic pGKL while they are expressible if the 5'non-coding regions are replaced by the UCS promoter $(11,12)$.

The pGKL plasmids normally locate in the cytoplasm, but relocate into the nucleus at a low frequency when forcibly selected for the expression of nuclear or foreign genes integrated on pGKL $(13,14)$. In $S$. cerevisiae, the nuclerly relocated plasmids replicate at multiple copies in either circular or linear form. The linear form, termed pTLU-type, lacks TP but carries the host telomeric repeats $(\mathrm{TG})_{1-6} \mathrm{TG}_{2-3}\left(\mathrm{TG}_{1-3}\right.$ in short) of about 300-350 bp long at the plasmid ends. This event was further studied using a monitor linear plasmid pCLU1 (8.4 $\mathrm{kb}$ ) carrying the cytoplasmic (UCS-ScLEU2) and the nuclear (ScURA3) markers on pGKL1 (15-17). Like pGKL1, pCLU1 normally replicates in the cytoplasm with the helper pGKL2. Thus, using a leu2 ura3 mutant as host, the relocation of pCLU1 into the nucleus could easily be assayed by the phenotypic change from $\mathrm{Leu}^{+} \mathrm{Ura}^{-}$to $\mathrm{Leu}^{-} \mathrm{Ura}^{+}$. Based on this rationale, a number of nuclearly relocated pCLU1-derivatives were selected from colonies growing on uracil lacking medium. This paper describes an effective use of pGKL-based linear plasmids in structural and functional study of telomeric

C 2003. Biological Procedures Online. Published in Biological Procedures Online under license from the author(s). Copying, printing, redistribution and storage permitted. 
sequences and includes a protocol for a simultaneous sequencing analysis of telomeres at both the plasmid ends.

\section{MATERIALS AND METHODS}

\section{Strain}

K12-PC (MAT a leu2 ura3 $\rho^{+}$pCLU1 pGKL2) of $S$. cerevisiae was used.

\section{Media}

Yeast cells were grown in a complete synthetic medium SC (0.67\% Difco nitrogen base without amino acids, $2 \%$ glucose, supplemented with $30 \mathrm{mg} / \mathrm{l}$ leucine and $50 \mathrm{mg} / 1$ uracil), or a selective medium SC-Ura (SC without uracil). Difco agar (2\%) was added for solid medium.

\section{Plasmids}

The linear plasmid pCLU1 was constructed by integrating the cytoplasmic promoter(UCS)-fused $L E U 2$ and the native $U R A 3$ genes into the non-essential ORF3-region of pGKL1 (15). pCLU1 carried terminal-protein (TP) at both ends and were normally maintained in the cytoplasm with the helper pGKL2. When relocated into the nucleus, however, pCLU1 replicated in a circular form (termed pRLU) or telomere-associated linear form (termed pTLU) independent of pGKL2 (18).

\section{Plasmid stability}

Cells harboring pTLU were suspended in sterile water, and appropriate dilutions were spread on SC-Ura and SC. Plasmid stability was estimated based on the ratio of the numbers of colonies produced on the two media.

\section{PCR amplification and telomere sequencing}

PCR and DNA sequencing of telomeric repeats at the plasmid ends are described in detail in the attached protocol. Briefly, the left and right end DNAs of pTLU were amplified by PCR, respectively, using primers \#1 (5'CACACACCACACCCACACAC3') and \#2 (5'GAATCAAAGTCGGCATATAC3'), and primers \#1 and \#3 (5'GGACTTAATGATATACCTAGAG3'), as shown in Fig. 1. The primer \#1 was complementary to a major telomeric motif 5'TGTGTGGGTGTGG3' while the primers \#2 and \#3 were complementary to nucleotide sequences between the positions 276 to 295 inward from the left ITR end and between the positions 471 to 492 inward from the right ITR end, respectively. Telomere sequencing was done by the chain termination method (19) with primer \#4 (5'GTATAATAAAATGACTTATAGG3') complementary to nucleotide sequence between the positions 171 to 192 inward from ITR both ends, using an automated sequencer (ABI373S, PE, Applied Biosystems) and a Dye Terminator Cycle
Sequencing Ready Reaction kit (PE Applied Biosystems).

\section{RESULTS AND DISCUSSION}

\section{Results}

\section{Isolation of nuclearly relocated linear plasmids}

The S. cerevisiae strain K12-PC was initially unable to grow on SC-Ura, because the URA3 gene on the endogeneous pCLU1 did not function in the cytoplasm. After prolonged (5-6 days) culture at $30^{\circ} \mathrm{C}$, however, a small number of colonies appeared, indicating the relocation of pCLU1 into the nucleus at a frequency of about $10^{-3}$. Thus, we isolated a number of $\mathrm{Ura}^{+}$clones, which carry nuclearly relocated plasmids. Since most of these $\mathrm{Ura}^{+}$clones could still contain pCLU1 and pGKL2 in the cytoplasm, cells were subjected to UV irradiation to remove them (a low-dose of UV-light efficiently eliminates the cytoplasmic plasmids without causing impairment of host cells (20)). Plasmid DNAs were extracted and analyzed to differentiate the pTLU-type (telomereassociated linear) from the pRLU1-type (circular), based on restriction analysis and Southern blotting with a telomere probe. The telomere-association at the plasmid ends was observed in rad52 mutant of $S$. cerevisiae $(16,17)$, but not in telomerase-subunit mutants of TLC1 encoding RNA template (21) and EST2 encoding reverse-transcriptase (22), as shown in Table 1. Only circularized plasmids were found in these mutants while the frequency of the plasmid relocation into the nucleus was not affected, supporting the view that the event was due to the action of host telomerase rather than RAD52dependent recombination with chromosomal telomeric repeats.

\section{Sequence analysis of telomeric DNA}

Restriction and Southern blot analyses showed that the pTLU plasmids from $\mathrm{Ura}^{+}$clones were structurally identical to pCLU1 except the addition of telomeric DNA (300-350 bp) at both ends, as shown in Fig. $1(15,16)$. To clarify the mechanism of terminal telomeric addition, the pTLU plasmids (pTLU1 to pTLU4) from four independent $\mathrm{Ura}^{+}$clones were subjected to sequence analysis for about $100 \mathrm{bp}$ of the telomeric DNA adjacent to the left and the right ITRs of plasmids. The results are given in Fig. 2, providing the following information. (I) In all cases, the terminally added telomere sequences basically consisted of $(\mathrm{TG})_{1-6} \mathrm{TG}_{2-3}$ (or $\left.\mathrm{TG}_{1-3}\right)$ in accordance with the host telomere DNA $(23,24)$, showing repeats of a major motif 5'TGTGTGGGTGTGG3'(13 bp) or 5'TGTGGGTGTGG3'(11 bp) which is complementary to part of nucleotides within the $T L C l$-encoded RNA template of host telomerase (21). (II) The telomeric DNAs were directly added to the very ends of the left and the right ITRs. (III) The TG organization in the added $\mathrm{TG}_{1-3}$ sequence varied among pTLU plasmids from different $\mathrm{Ura}^{+}$clones, but surprisingly, 
(IV) it was symmetrically identical on both ends of any one plasmid.

The variation in the TG organization among pTLUs in (III) probably comes from the nucleotide heterogeneity of RNAtemplate $(21,23)$ or due to a primer-template slippage or nonprocessive telomere synthesis $(25,26)$. The ITR-end telomere-addition in (II) and the symmetrical telomeric sequences at both ends in (IV) may be explained as in Fig. 3: that is, a) the juxtaposition of the termianlly separated ITR regions according to the racket frame-shape model of invertron elements (27), b) the 3' single-stranded overhanging of ITRend by an action of a 5'-3' exonuclease, following loss of TP, c) the telomeric addition by telomerase to one of both ITR ends using the 3' ITR-end overhang (5'...TGTGT3') as substrate, d) the formation of complementary strand by DNA polymerase, and e) the single-strand invasion and copy-transfer of the telomere added to one plasmid end into another ITR end (16). The ITR-end association of telomeric repeats was constantly observed in a variety of strains of $S$. cerevisiae, either wildtype or telomere-related mutants such as tell, mrel, exo (data not shown), emphasizing that the ITR-end sequence TGTGT played a crucial role in the telomere-addition, probably as a primer for telomere elongation.

\section{Clonal analysis of $\mathrm{Ura}^{+}$clones carrying $\mathrm{pTLU}$}

Like the ends of eukaryote chromosomes, pTLU-telomeres would undergo the terminal shortening and DNA repair during cell division. Thus, after some cell proliferation, a sequence rearrangement is expected to occur in the pTLU-telomeric repeats. Hereupon, a drastic rearrangement would afffect the telomere function and may result in instability or a total loss of the pTLU plasmid. In fact, when cells of K12-PT2 (K12-PC derived strain harboring a telomere plasmid pTLU2, Fig. 2) were grown on SC and plated on selective medium SC-Ura, a mixture of large and small (slow-growing) colonies was produced while the colonies were uniformaly large when plated on SC. Clonal analysis showed that the slow growing trait of small colonies resulted from low expression of the URA3 gene due to instability of the endogeneous pTLU siblings whereas large colonies on SC-Ura constantly contained cells with relatively stable pTLU. A possibility that the low expression of the URA3 gene may be due to a position effect of the nearby telomeric sequence $(28,29)$ was ruled out by the fact that $\mathrm{Ura}^{-}$clones growing on $\mathrm{SC}$ with 5 -fluoroorotic acid (30) were all devoid of pTLU plasmids (17).

\section{Progressive rearrangement of telomeric sequence}

To check the above problem, six large and eight small colonies of K12-PT2 growing on SC-Ura were picked up, and the endogeneous pTLU plasmids were extracted to analyze the telomeric sequences at both ends. Knowing that the telomeric size of pTLU from these clones was about 300-350 bp long, similar to that of the original pTLU2, the ITR-adjacent telomeric nucleotides of about $100 \mathrm{bp}$ long were sequenced. As a result, all pTLU siblings from six large colonies were found to have telomeric repeats identical to those of the original pTLU2 (data not shown). Of the eight pTLU plasmids from small colonies, three had the same telomere sequence as pTLU2 (data not shown). However, the remaining five (pTLU2/S1 to pTLU2/S5) were deviated from pTLU2, as shown in Fig. 4. In fact, they differed in the $\mathrm{TG}_{1-3}$ organization over a wide range, extending from the telomeric end to various internal sites (positions 70-52) and varying in the number and order of the TG tract flanked by the TGG and/or TGGG array.

Unexpectedly, the telomere rearrangement in the above five pTLU siblings was observed only on one side of the plasmid ends (the left in pTLU2/S1 to pTLU2/S3, and the right in pTLU2/S4 and pTLU2/S5), while the opposite sides remained identical to that of pTLU2. Given that the telomeric rearrangement reflects the 5 'terminal shortening and gap-repair by telomerase, the $\mathrm{TG}_{1-3}$ variation in the above (also in Figs. 5 and 6) ought to extend from the indicated internal rearrangement sites to the far end of added telomeres of 300$350 \mathrm{bp}$ long.

\section{$A$ variety of telomeric rearrangement}

It was suggested from the above results that pTLU2 of the parental strain underwent a variety of telomeric rearrangements during cell growth on non-selective medium, yielding slowgrowing clones on SC-Ura. To reconfirm this observation, one of large colonies on SC-Ura, carrying the original pTLU2, was plated on a complete medium (SC) for single colonies. The size of colonies formed was uniformly large. Nine clones (K12-PT2/C1 to /C9) were isolated at random and streakcultured on SC for 2 days. Then, the cells were subjected to the assay of the stability of the endogeneous pTLU2-derived siblings and their telomeric DNA sequencing. It was found that the pTLU2-siblings (pTLU2/C2, /C3 and /C7) from the three clones (K12-PT2/C2, /C3 and /C7) were highly unstable (0.16, $0.25,0.6 \%$, respectively) and had telomeric $\mathrm{TG}_{1-3}$ organization distinct from pTLU2 and from each other (Fig. 5A). The rearranged sequences ranged from the various ITR proximal positions $(60,47$ and 77$)$ toward the telomeric ends, respectively. Here again, the telomeric rearrangements were observed only on one side of the plasmids: the left in pTLU2/C2 and the right in pTLU2/C3 and /C7. In contrast, the pTLU2-siblings from the remaining six clones (K12-PT2/C1, $/ \mathrm{C} 4$ to $/ \mathrm{C} 6, / \mathrm{C} 8, / \mathrm{C} 9)$ were more stable $(34-9 \%, 22 \%$ on the average) and contained the same telomeric repeats as the original pTLU2 as far as telomeric nucleotides of about $100 \mathrm{bp}$ were examined (data not shown).

To study more of the relationship between the stability and telomeric rearrangement, the second round of assays was carried out with pTLU2-siblings from each of one stable clone $\mathrm{K} 12-\mathrm{PT} 2 / \mathrm{C} 1$ and three unstable clones K12-PT2/C2, /C3, and /C7. To this end, cells grown on SC-Ura were plated on SC for single colonies, and the resulting eight subclones were examined each. The telomeric assay of about $100 \mathrm{bp}$ adjacent 
to ITRs showed that, of the eight K12-PT2/C1-subclones, six had pTLU identical to pTLU2 (data not shown) with stability of $31-34 \%$, close to that of pTLU2 from K12-PT2/C1. However, pTLU (pTLU2/C1-2 and pTLU2/C1-3) from the remaining two subclones differed from pTLU2 on the left side, both ranging from the identical ITR proximal position (60) toward the ends (Fig. 5B). Their stability was 17 and $9 \%$, respectively, lower than that of the above six related subclones, but significantly higher than the stability $(0.16,0.25,0.6 \%)$ of pTLU2 siblings from K12-PT2/C2, /C3 and /C7, described above. We presume that this extreme instability of the latter three pTLU2-siblings in the first round assay was due to the conditions of cell growth prior to the stability assay: that is, pTLU2 siblings from $\mathrm{K} 12-\mathrm{PT} 2 / \mathrm{C} 1$ to $/ \mathrm{C} 9$ were generally unstable, because their stability was estimated after repeated cell growth on SC, which allowed an accumulation of pTLUcured cells or cells with pTLU of low stability.

On the other hand, of eight subclones of unstable K12-PT2/C2, $/ \mathrm{C} 3$, and /C7 each, five carried the rearranged telomeric sequence on one side (Fig. 5B). Notably, in all these cases, the $\mathrm{TG}_{1-3}$ rearrangement proceeded toward more internal regions than those of their parental clones: for example, the positions $45,41,52,60,29$ in each of pTLU2/C2-2, /C2-4, /C2-5, /C2-6, /C2-8 against the position 60 in pTLU2/C2. The position 60 in pTLU2/C2-6 was identical to that of the parental pTLU2/C2, but the $\mathrm{TG}_{1-3}$ organization differed between them. The results imply that the telomere end shortening and repair have continuously advanced toward the inner side during cell growth. Moreover, the stability was extremely reduced in these plasmids: $0.01-0.08 \%$ in pTLU2/C2-siblings, $0.01-0.1 \%$ in pTLU2/C3-siblings, and $0.01-0.1 \%$ in pTLU2/C7-siblings, much lower than data of their parental clones, revealing that the decrease in stability was closely related to the progressive telomeric rearrangements. Throughout this experiment, there was no telomeric rearrangement on the opposite side.

\section{Time course of telomeric rearrangement}

The above assay demonstrated that the $\mathrm{TG}_{1-3}$ rearrangement occurred in principle on one side of the pTLU plasmid ends during cell growth. To analyze the time-course of this event, the three clones K12-PT2/C2, /C3, and /C7 each were streakcultured on SC consecutively at intervals of 24 hours (about 10 generations) and examined for the telomeric sequence. The results are given in Fig. 6, showing that the telomeric sequence remained unchanged for the first 10 generations. After 20-50 generations, however, a novel $\mathrm{TG}_{1-3}$ organization was detected on the same telomeric sequence, which had a previous rearrangement. It is also notable that, after 50 generations, the second rearrangement occurred from the outside of the previously rearranged telomeric sequence. In contrast, if the above assay was done on SC-Ura, there was no observation of telomeric rearrangement even after 50 or more generations (data not shown). In this case, we presume that telomere rearrangements must actually have occurred in clones growing on SC-Ura as well, but that they could not be detected because the pTLU with rearranged telomeres were highly unstable and thus because the culture was mostly predominated by cells with stably replicating pTLU2 of the original type.

\section{Discussion}

Relocation of the yeast cytoplasmic linear plasmids into the nucleus was assayed using a monitor plasmid pCLU1 in terms of the phenotypic change of the integrated markers (the UCSfused $L E U 2$ and the native URA3) in S. cerevisiae (leu2 ura3). The nuclearly relocated pCLU1 replicated in either circular or linear form. While the circular form resulted from pCLU1 by ITR-involved intramolecular recombination or transposon-like invasion (18), the linear plasmid pTLU was created by an addition of the host telomeric repeats at both ends of pCLU1 $(15,16)$.

The telomere addition occurred in rad52 mutant $(16,17)$, but not in tlcl and est 2 mutants, strongly suggesting the involvement of host telomerase rather than recombination with chromosome telomeric repeats. While the $\mathrm{TG}_{1-3}$ organization varied among the individual pTLU plasmids, it was symmetrically identical at the left and the right ends of any one pTLU. This probably arose from a unique process of telomere addition to a racket-frame shaped linear plasmid of an invertron-type, as illustrated in Fig. 3.

Like the chromosome ends, the telomere sequence of pTLU should undergo successive rearrangements due to incomplete DNA replication at the 5 'end and subsequent DNA repair by telomerase. In our experiment, the pTLU-derived plasmids with the rearranged $\mathrm{TG}_{1-3}$ sequence were unstable, and the instability was much enhanced with increasing in the rearrangement. Thus, when cells were grown on SC-Ura, the telomere of original pTLU type was predominantly selected by surpassing unstable pTLU-siblings. Supposing that the telomeric repeats added to pTLU was about 300-350 bp long, and that the telomere rearrangement resulted from successsive rounds of terminal shortening and end healing by the aid of telomerase, we estimate that the pTLU plasmids underwent the telomere rearrangement over a wide range of around $300 \mathrm{bp}$ inward from the far end during this experiment, reaching the ITR proximal positions between 29 and 77 on the assayed telomeres (Figs. 5 and 6). Such over-shortening or a wideranged rearrangement of telomeric sequences might be detrimental to the integrity of pTLU plasmids and may have caused an extreme instability of the linear plasmids.

Progressive rearrangement of $\mathrm{TG}_{1-3}$ sequence on one side of pTLU ends was of special interest, implying that the mode of telomeric replication or end-shortening/repair may be different between both ends. It appears that the event is subject to condition of end-shortening and repair. For example, if the repair at one end is delayed or impaired for some reason, the end-shortening would continue toward more inner region while the opposite end is repaired normally. Thus, in the present study where telomeric sequence assay was conducted for about 
$100 \mathrm{bp}$ adjacent to the ITR ends, the telomeric rearrangement was detectable on one side, as given in Fig. 7.

A variety of genes or gene products are known to interact with the telomere function and its length control. In $S$. cerevisiae, the Rap1, Est 1 and Est $4 / C d c 13$ products play important roles in regulation of telomere-length via telomerase activity (31-35) while proteins such as Sir3p, Sir4p, Riflp, and Rif2p interact with Rap $1 p$ and are involved in telomere integrity (36-38). The yeast $\mathrm{Ku}$ protein is required for telomere-clustering and its functional loss leads to the telomere-shortening (39-42). The TEL1 and TEL2 are essential genes required for telomerelength regulation $(43,44)$. Since pTLU exists in the nucleus as many as 30 copies per cell in a haploid strain of $S$. cerevisiae, the cell should have at least 90 telomeres by including the ends of 16 host chromosomes. Thus, a possibility arises that, under normal condition of cell growth, pTLU-plasmids may be short of such telomere-related proteins mentioned above due to their possible preferential recruitment to host chromosomes, and that it may cause a defect in the telomere function, the lengthcontrol or the stability of pTLU-plasmids. Although detailed mechanism for the one-sided telomere rearrangement observed in this study remains to be examined, the pGKL-based linear plasmids are highly unique in that they allow a simultaneous analysis of the telomere sequences at both ends.

\section{REFERENCES}

1. Fukuhara H. Linear DNA plasmids of yeasts. FEBS Microbiol Lett 1995; 131:1-9.

2. Gunge N. Linear DNA killer plasmids from the yeast Kluyveromyces. Yeast 1986; 2:153-162.

3. Gunge N. Plasmid DNA and the killer phenomenon in Kluyveromyces. In Kueck U (ed) Mycota II. Genetics and biochemistry. Springer-Verlag. Berlin and Heidelberg, 1995, pp. 189-209.

4. Meinhardt F, Schaffrath R. Extranuclear Inheritance: cytoplasmic linear double-stranded DNA killer elements of the dairy yeast Kluyveromyces lactis. In Progress in Botany, Vol 62, Eds. Esser K, Luettge U, Kadereit J, Beyschlag W, Springer-Verlag, Berlin, Heidelberg, New York, 2001, pp 51-70.

5. Salas M, Freire R, Soengas MS, Esteban JA, Mendez J, Bravo A, Serrano M, Blasco MA, Lazaro JM, Blanco L, Guitierrez C, Hermoso JM. Protein-nucleic acid interactions in bacteriophage $\phi 29$ DNA replication. FEMS Microbiol Rev 1995; 17:73-82.

6. Stark MJR, Boyd A, Mileham A, Romanos MA. The plasmid-encoded killer system of Kluyveromyces lactis: a review. Yeast 1990; 6:1-29.

7. Romanos M, Boyd A. A transcriptional barrier to expression of cloned toxin genes of the linear plasmid $\mathrm{k} 1$ of Kluyveromyces lactis: evidence that native $\mathrm{k} 1$ has novel promoters. Nucleic Acids Res 1988; 16:7333-7350.

8. Sor F, Fukuhara H. Structure of a linear plasmid of the yeast Kluyveromyces lactis: compact organization of the killer genome. Curr Genet 1985; 9:147-155.

9. Tiggermann M, Jeske S, Larsen M, Meinhardt F. Kluyveromyces lactis cytoplasmic plasmid pGKL2: heterologous expression of ORF3p and proof of guanylyltransferase and mRNA-triphosphqatase activities. Yeast 2001; 18:815-825.

10. Stam JC, Kwakman J, Meijer M, Stuije AR. Efficient isolation of the linear DNA killer plasmid of Kluyveromyces lactis: evidence for location and expression in the cytoplasm and characterization of their terminally bound proteins. Nucleic Acids Res 1986; 14:6871-6884.

11. Kaemper J, Meinhardt F, Gunge N, Esser K. Heterologous gene expression on the linear DNA killer plasmid from Kluyveromyces lactis. Curr Genet 1991; 19:109-118.

12. Tanguy-Rougeau C, Chen XJ, Wesolowski-Louvel M, Fukuhara H. Expression of a foreign $\mathrm{Km}^{\mathrm{R}}$ gene in linear killer DNA plasmids in yeast. Gene 1990; 91:43-50.

13. Fujimura H, Hishinuma F, Gunge N. Terminal segment of Kluyveromyces lactis linear DNA plasmid pGKL2 supports autonomous replication of hybrid plasmids in Saccharomyces cerevisiae. Curr Genet 1987; 12:99-104.

14. Kaemper J, Meinhardt F, Gunge N, Esser K. In vivo construction of linear vectors based on killer plasmids from Kluyveromyces lactis: selection of a nuclear gene results in attachment of telomeres. Mol Cell Biol 1989; 9: 3931-3937.

15. Gunge N, Fukuda K, Takahashi S, Meinhardt $M$. Migration of the yeast linear DNA plasmid from the cytoplasm into the nucleus in Saccharomyces cerevisiae. Curr Genet 1995; 28:280-288.

16. Takata H, Fukuda K, Meinhardt F, Gunge N. Telomere sequences attached to nuclearly migrated yeast linear plasmid. Plasmid 2000; 43:137-143.

17. Takata H, Gunge N. Progressive alteration of telomeric sequences at one end of a yeast linear plasmid and its possible association with reduced plasmid stability. Mol Genet Genomics 2001; 266:686-694.

18. Gunge N, Takata H, Fukuda K, Iwao S, Miyakawa I. Relocation of a cytoplasmic yeast linear plasmid to the nucleus is associated with circularization via nonhomologous recombination involving inverted terminal repeats. Mol Gen Genet 2000; 263:846-853.

19. Sanger F, Nicklen S, Coulson AR. DNA sequencing with chain-terminating inhibitors. Proc Natl Acad Sci USA 1977; 74:5463-5467.

20. Gunge N, Takahashi S, Fukuda K, Meinhardt F. UV hypersensitivity of yeast linear plasmids. Curr Genet 1994; 26:369-373.

21. Singer MS, Gottschling DE. TLC1: template RNA component of Saccharomyces cerevisiae telomerase. Science 1994; 266:404-409.

22. Linger J, Hughes TR, Shevchenko A, Mann M, Lundblad, V, Cech TR. Reverse transcriptase motifs in the catalytic subunit of telomerase. Science 1997; 276:561567.

23. McEachern MJ. Blackburn EH. A conserved sequence 
motif within the exceptionally diverse telomeric sequences of budding yeasts. Proc Natl Acad Sci USA 1994; 91:3453-3457.

24. Zakian VA. Saccharomyces telomeres: function, structure and replication. In Blackburn EH and Greider CW (eds) Telomerases. Cold Spring Harbor Lab Press, 1995, pp. 107-137.

25. Prescott J, Blackburn EH. Telomerase RNA mutations in Saccharomyces cerevisiae alter telomerase action and reveal nonprocessivity in vivo and in vitro. Genes \& Develop 1997; 11:528-540.

26. Foerstemann K, Linger J. Molecular basis for telomere repeat divergence in budding yeast. Mol Cell Biol 2001; 21:7277-7286.

27. Sakaguchi K. Invertrons, a class of structurally and functionally related genetic elements that includes linear DNA plasmids, transposable elements, and genomes of adeno-type viruses. Microbiol Rev 1990; 54:66-74.

28. Gottschling DE, Aparicio OM, Billington BL, Zakian VA. Position effect at $S$. cerevisiae telomeres: reversible repression of POL II transcription. Cell 1990; 63:751-762.

29. Longtine MS, Enomoto S, Finstad SL, Berman J. Telomere-mediated plasmid segregation in Saccharomyces cerevisiae involves gene products required for transcription repression at silencers and telomeres. Genetics 1993; 133:171-182.

30. Boek JD, LaCroute F, Fink GR. A positive selection for mutants lacking orotidine-5'-phosphate decarboxylase activity in yeast: 5'-fluoroorotic acid resistance. Mol Gen Genet 1984; 197:345-346.

31. Conrad NM, Wright JH, Wolf AJ, Zakian VA. RAP1 protein interacts with yeast telomeres in vivo: overproduction alters telomere structure and decreases chromosome stability. Cell 1990; 63:739-750.

32. Kyrion G, Boakye KA, Lustig AJ. C-terminal truncation of RAP1 results in the deregulation of telomere size, stability, and function in Saccharomyces cerevisiae. Mol Cell Biol 1992; 12:5159-5173.

33. Lendvay TS, Morris DK, Sah J, Balasubramanian B, Lundblad V. Sequence mutations of Saccharomyces cerevisiae with a defect in telomere replication identify three additional EST genes. Genetics 1996; 144:13991412.

34. Ray A, Runge $\mathrm{KW}$. The $\mathrm{C}$ terminus of the major yeast telomere binding protein Rap1 enhances telomere formation. Mol Cell Biol 1998; 18:1284-1295.

35. Virta-Pearlman V, Morris DK, Lundblad V. Est1 has the properties of a single-stranded telomere end-binding protein. Genes \& Develop 1996; 10:3094-3104.

36. Louis EJ. The chromosome ends of Saccharomyces cerevisiae. Yeast 1995; 11:1553-1573.

37. Palladino F, Lacroche T, Gilson E, Axelrod A, Pillus L, Gasser M. Sir3 and Sir4 proteins are required for the positioning and integrity of yeast telomeres. Cell 1993; 75:543-555.

38. Wotton D, Shore D. Novel Rap1p-interacting factor, Rif2p, cooperates with Rif1p to regulate telomere length in
Saccharomyces cerevisiae. Genes \& Develop 1997; 11:748-760.

39. Gravel S, Larrivee M, Labrecque P, Wellinger RJ. Yeast ku as a regulator of chromosomal DNA end structure. Science 1998; 280:741-744.

40. Laroche T, Martin SG, Gotta M, Gorham HC, Pryde FE, Louis EJ, Gasser SM. Mutation of yeast Ku genes disrupts the subnuclear organization of telomeres. Curr Biol 1998; 8:653-656.

41. Nugent CI, Bosco G, Ross LO, Evans SK, Salinger AP, Moore JK, Haber JE, Lundblad V. Telomere maintenance is dependent on activities required for end repair of double-strand breaks. Curr Biol 1998; 8:657-660.

42. Ritchie KB, Mallory JC, Petes TD. Interaction of TLC1 (which encodes the RNA subunit of telomerase), TEL1, and $M E C 1$ in regulating telomere length in the yeast Saccharomyces cerevisiae. Mol Cell Biol 1999; 19:60656075.

43. Greenwell PW, Kronmal SL, Porter SE, Gassenhuber J, Obermarie B, Petes TD. TEL1, a gene involved in controlling telomere length in S. cerevisiae, is homologous to the human ataxia telangiectasis gene. Cell 1995; 82:823-829.

44. Runge KW, Zakian VA. TEL2, an essential gene required for telomere length regulation and telomere position effect in Saccharomyces cerevisiae. Mol Cell Biol 1996; 16:3094-3105. 
FIGURES AND TABLE

\section{pCLU1 (8.4 kb)}

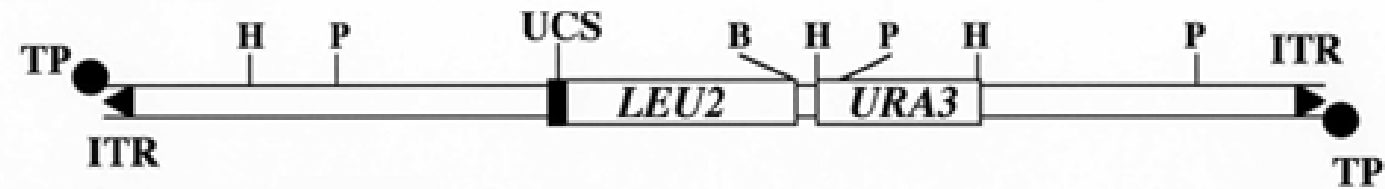

pTLU (9.0 kb)

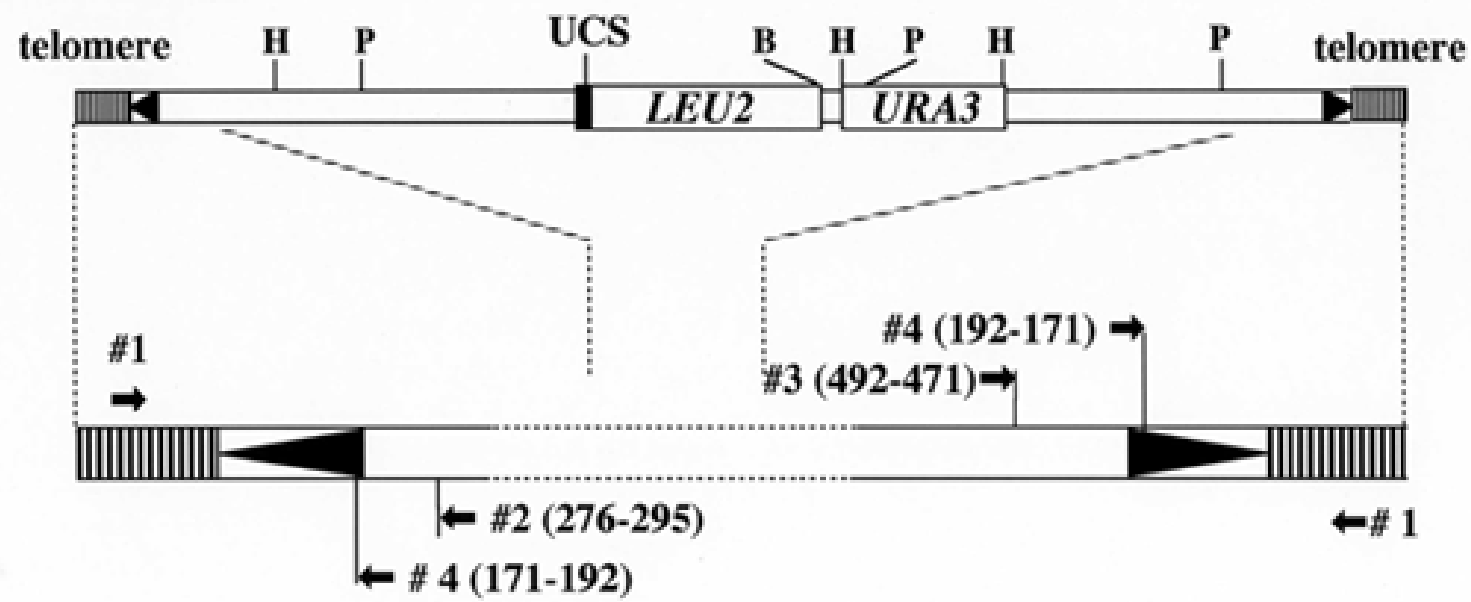

Fig. 1: Plasmid structure and strategy for DNA sequencing of the telomeric repeats at both ends of pTLU. Telomeric DNA sequences at the ITR ends were prepared and analyzed as in MATERIALS and METHODS. Arrow of the primer indicates the direction of the sequence elongation. Closed triangles on the plasmid ends, ITRs (202 bp); striped square, terminally added telomere; B, BamHI; H, HindIII; P, PstI.

ITR

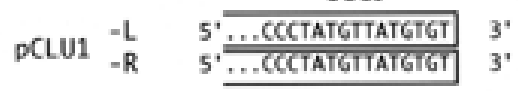

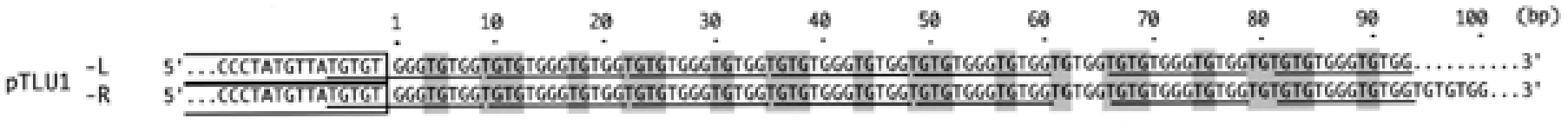

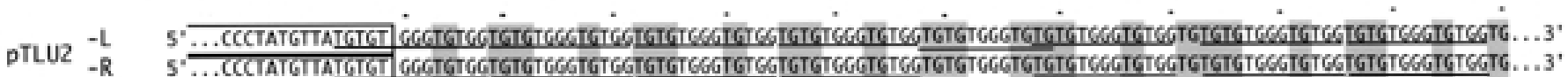

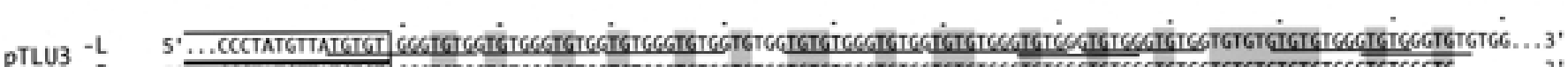

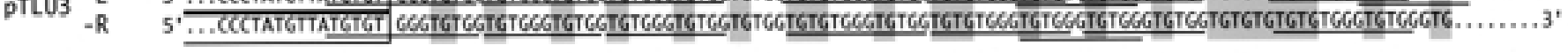

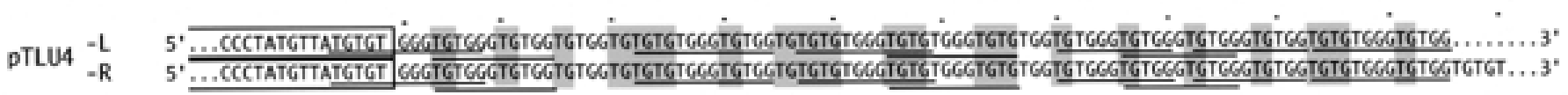

Fig. 2: Telomere-sequences added to the ITR ends. Sequences are presented in the $5^{\prime}$ to $3^{\prime}$ direction from ITR toward the termini of added telomere $\left(\mathrm{TG}_{1-6} \mathrm{TG}_{2-3}\right.$. $\mathrm{L}$ and $\mathrm{R}$ denote the left and the right ends of pTLU-type plasmids, respectively. The major telomeric motif (5'TGTGTGGGTGTGG3') is underlined. The TGdinucleotide tract flanked by TGG and TGGG is shaded. Modified citation from Takata et al. (2000). 
$\mathbf{A}$

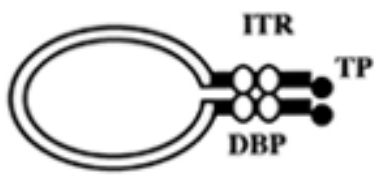

B

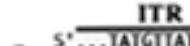

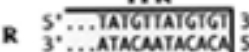

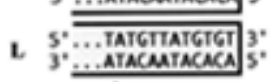

$5^{*} \rightarrow 3^{\prime}$ exonuclease

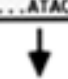

(1D)

3' exonuclease

R

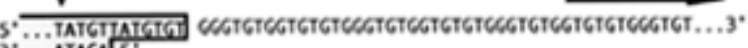

"mATACA 5

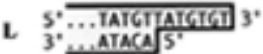

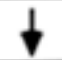

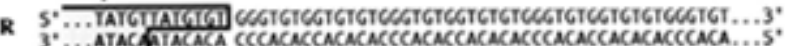

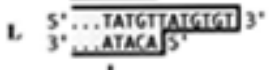

DNA polymerase

$\mathbf{R}$

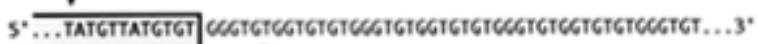

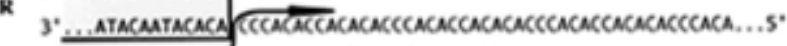

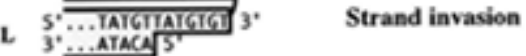

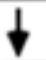

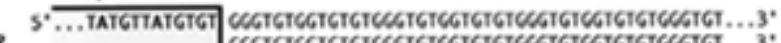

R

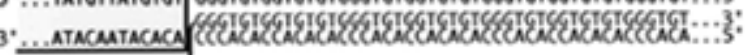

L.

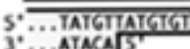

$\frac{1}{t}$

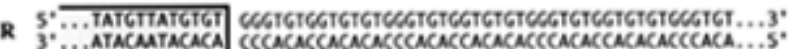

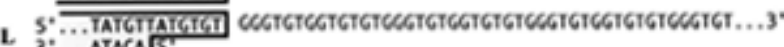

2 ....ATACA 5

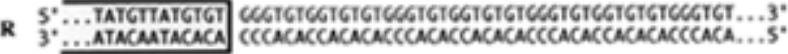

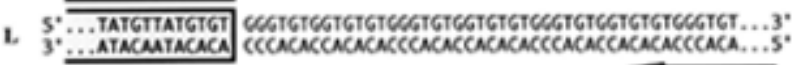

\section{DNA polymerase}

Fig. 3: Mechanism of creation of symmetrical telomeric sequences at both ends. A. Racket frame shape model of pTLU. B. Creation of identical telomere sequences at the ITR ends. Telomerase activity requires a single-strand tail as a primer to initiate the telomere elongation, so the ITR ends are deprived of TP and partially digested by a 5' to 3' endonuclease to create a short 3' single-strand overhang with TGTGT nucleotides. See text.

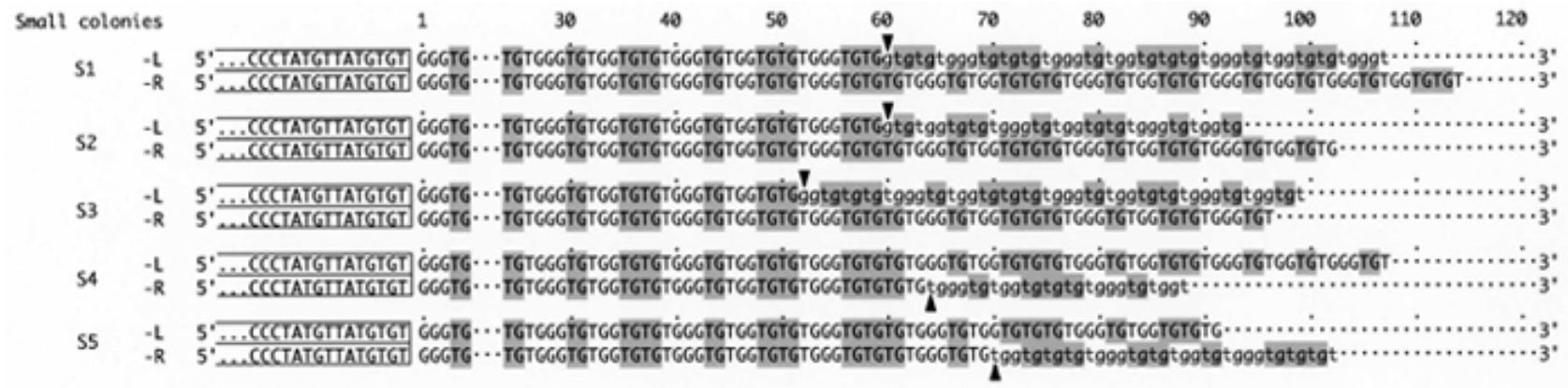

Fig. 4: Telomeric sequences of pTLU2-siblings recovered from slow-growing colonies of K12-PT2. Upper and lower case letters denote the original and rearranged telomeric sequences, respectively. The filled triangles indicate the ITR proximal positions of rearranged telomeric sequence. The nucleotide sequence between positions 6 to 23 was the same in all plasmids and omitted for simplicity. In this study, the telomere sequences were determined for about 100 bp adjacent to the ITR, but the rearrrangement should presumably continue toward the 3 'termini of added telomere, which is indicated by the broken lines. Other symbols are as in Fig. 2. Modified citation from Takata and Gunge (2001).

Biological Procedures Online • Vol. 5 No. $1 \bullet$ February 17, 2003•www.biologicalprocedures.com 
A

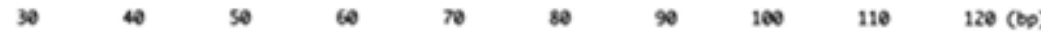

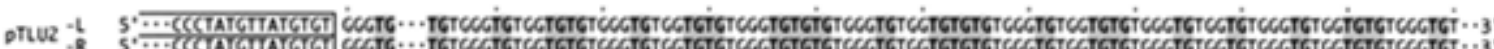

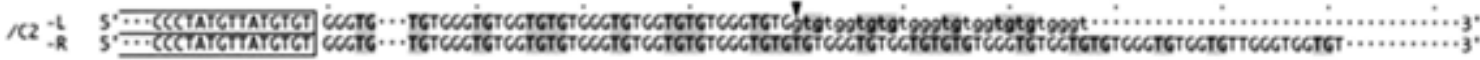

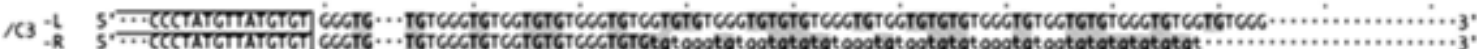
-R 5 '

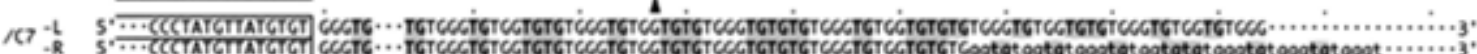

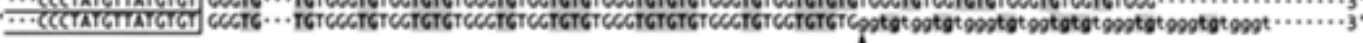

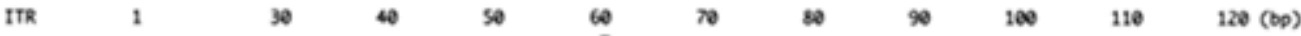

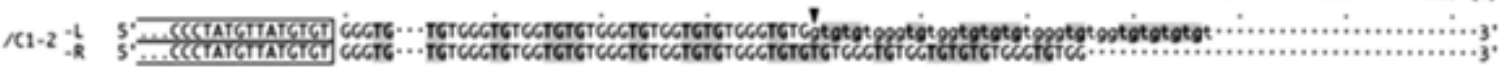

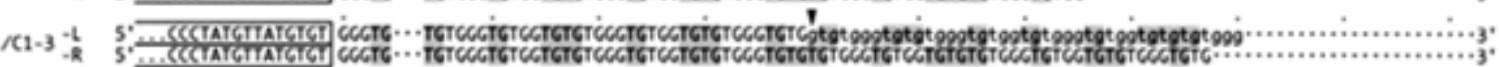

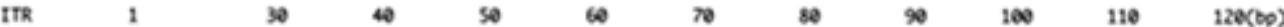

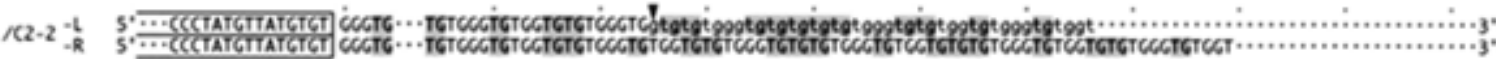

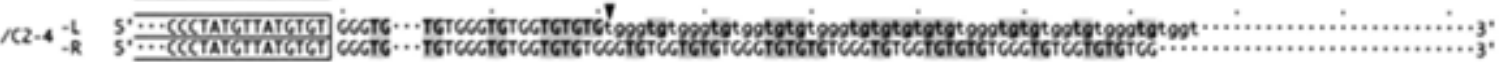

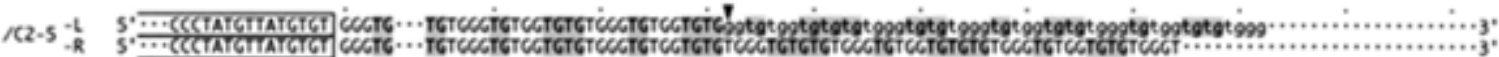

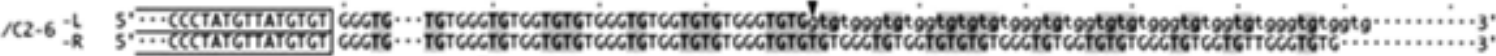

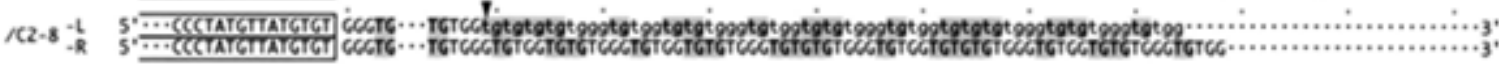
$\begin{array}{llllllllllll}\text { ITR } & 1 & 30 & 40 & 50 & 60 & 70 & s e & 90 & 100 & 110 & 120(6 \mathrm{p})\end{array}$

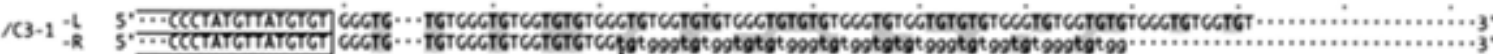

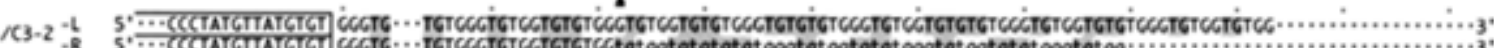

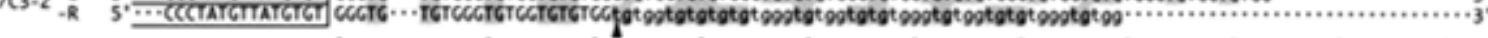

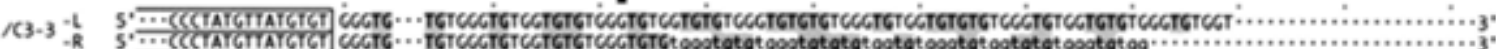

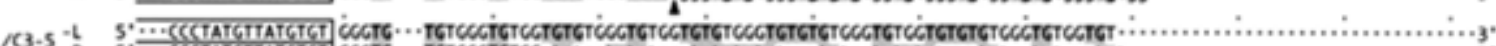

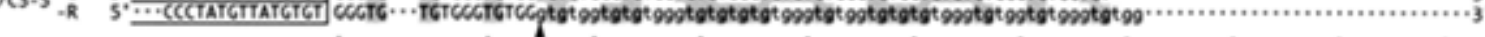

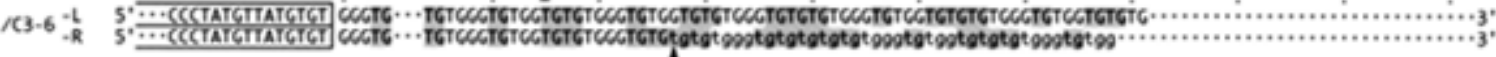

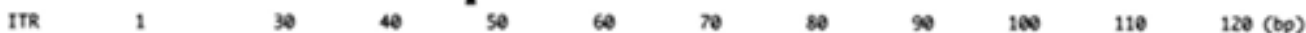

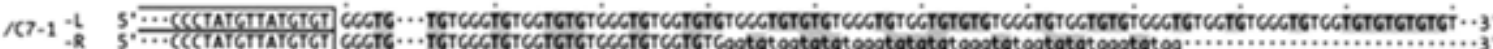

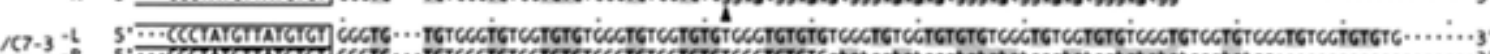

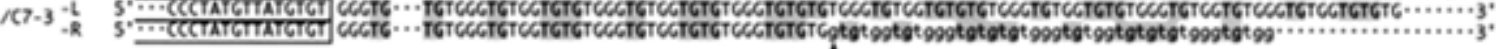

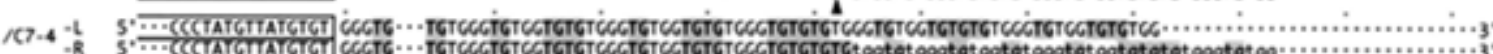

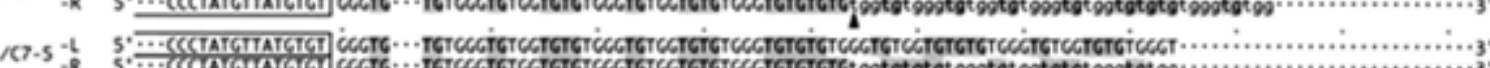

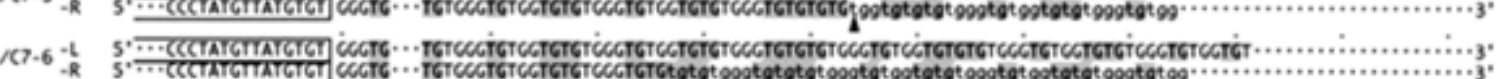

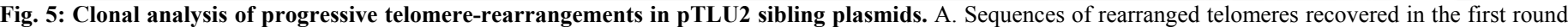

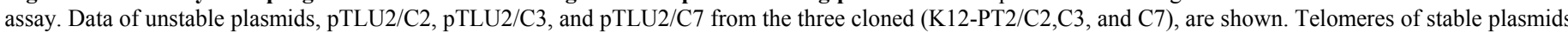

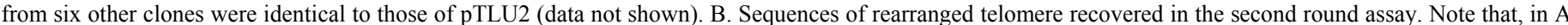

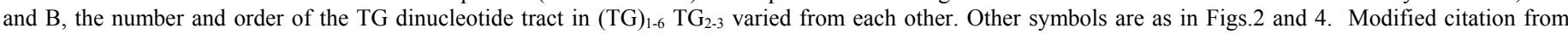
Takata and Gunge (2001)

Biological Procedures Online • Vol. 5 No. 1 • February 17, 2003 • www.biologicalprocedures.com 

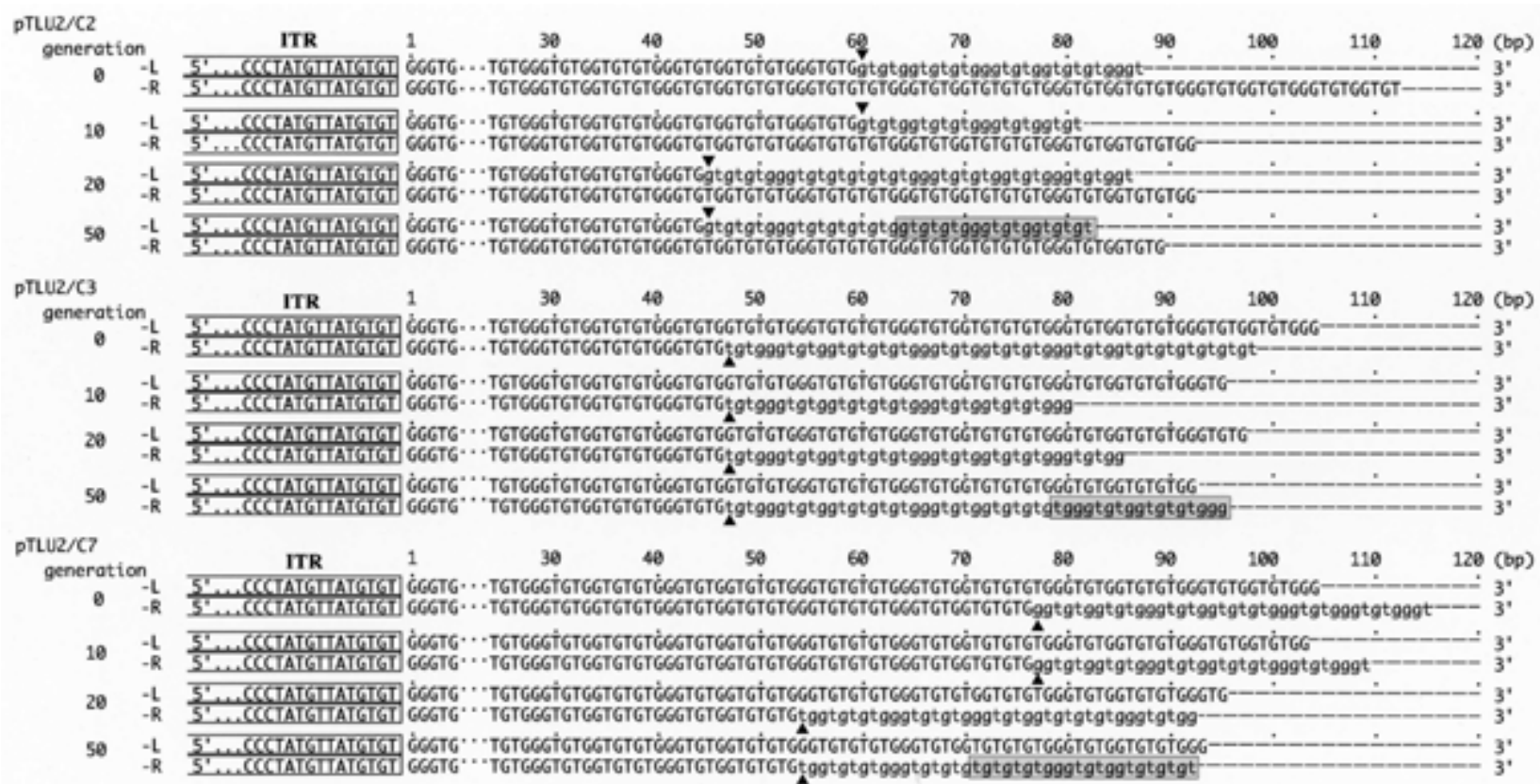

Fig. 6: Time course of progressive telomeric rearrangement. Additional telomeric rearrangements were detected after 20 and/or 50 generations. The shaded box (50 generations) indicates novel telomeric rearrangements occuring on the previous rearrangements. Other symbols are as in Fig. 4. Modified citation from Takata and Gunge (2001).

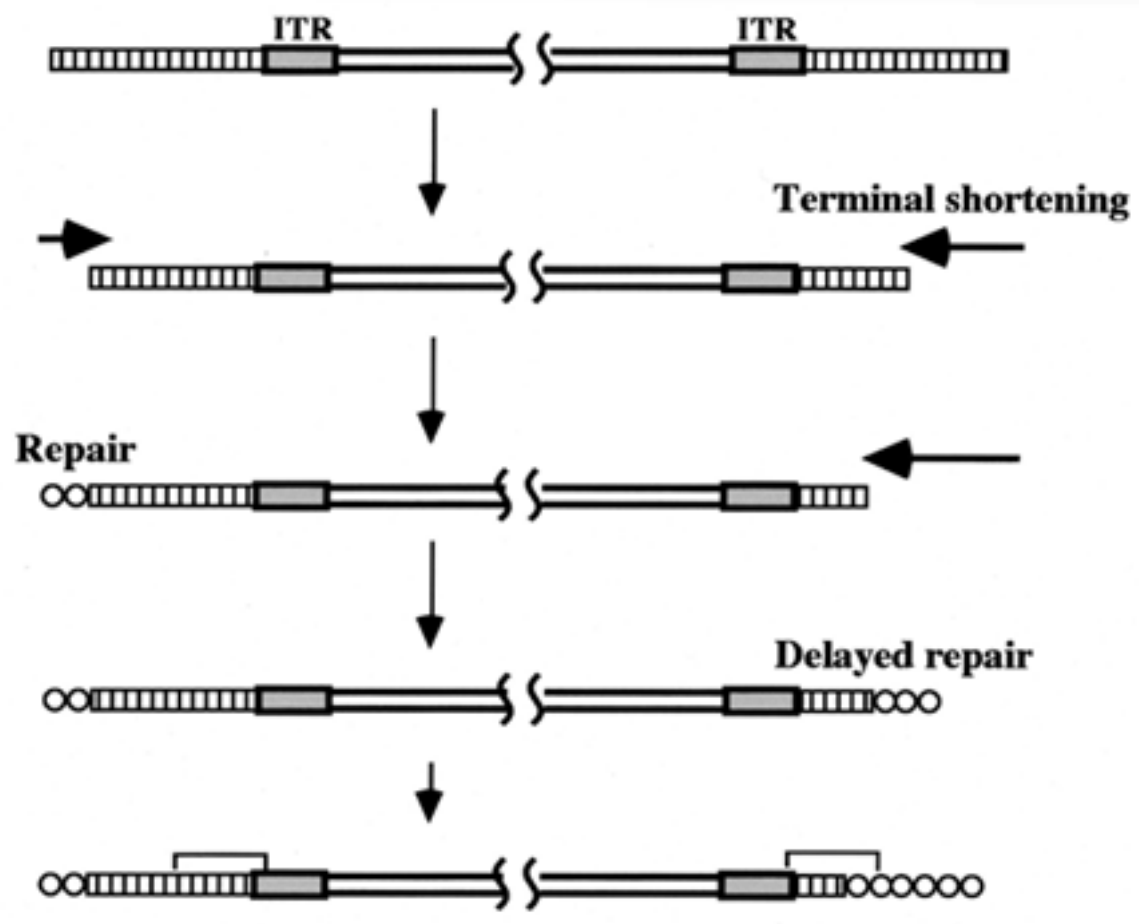

Fig. 7: A model of telomeric sequence rearrangement on one side. Open circles on telomere indicate rearranged telomeric repeats due to delayed repair. The square bracket, sequenced telomeric region.

Biological Procedures Online • Vol. 5 No. $1 \bullet$ February 17, 2003・www.biologicalprocedures.com 
Table 1: Frequencies of nuclear-relocation of pCLU1 and telomeric attachment at the ends

\begin{tabular}{lll}
\hline Strain & Nuclear relocation & \% of pTLU-type * \\
\hline K12-2A-PC (wild-type) & $1.1 \times 10^{-3}$ & $14(48)$ \\
A364a-PC (wild-type) & $1.1 \times 10^{-3}$ & $11(48)$ \\
S288C-PC (wild-type) & $1.0 \times 10^{-3}$ & $12(16)$ \\
W303-PC (wild-type) & $1.1 \times 10^{-3}$ & $14(16)$ \\
XS95-6C-PC (rad52) & $1.1 \times 10^{-3}$ & $13(32)$ \\
YPH499-PC (tlc1) & $1.0 \times 10^{-3}$ & $0(48)$ \\
BY4741-PC (est2) & $1.4 \times 10^{-3}$ & $0(48)$ \\
\hline
\end{tabular}

* Number of plasmids examined is given in parenthesis. 


\title{
PROTOCOLS
}

\section{Sequencing of telomeric DNA attached to the left and the right ITR ends of the yeast linear plasmid pTLU}

\author{
Strain used for telomere-sequencing
}

Saccharomyces cerevisiae K12-PT2 (Mata leu2 ura $3 \rho^{+}$pTLU).

This strain should be kept on medium SC-Ura to maintain the telomere-associated plasmid pTLU (pTLU carries a selective marker ScURA3).

\section{A. Isolation of DNA (A modification of Miniprep method in Methods in Yeast Genetics, CSH Laboratory, 1994 )}

1. Grow cells overnight in $5 \mathrm{ml}$ of medium SC-Ura.

2. Collect the cells in a microfuge at $2000 \mathrm{rpm}$ for 5 minutes. Discard the supernatant.

3. Resuspend the cells in $0.5 \mathrm{ml}$ of buffer ( $10 \mathrm{ml}$ EDTA, $2.5 \%$ 2-mercaptoethanol, $0.6 \mathrm{M} \mathrm{KCl}, \mathrm{pH} 8.0)$. Hold at room temperature for 5 minutes.

4. Centrifugation at $2000 \mathrm{rpm}$ for 5 minutes and discard the supernatant.

5. Add $0.3 \mathrm{ml}$ of a lysis buffer (0.1 M EDTA, $33 \mathrm{mM}$ Tris- $\mathrm{HCl}(\mathrm{pH} 8.0), 0.6 \mathrm{M} \mathrm{KCl}, 0.03 \%$ 2-mercaptoethanol, $0.4 \mathrm{mg} / \mathrm{ml}$ Zymolyase 20T) and incubate at $37^{\circ} \mathrm{C}$ for 30 minutes.

6. Centrifuge in a microfuge at $3000 \mathrm{rpm}$ for 1 minute. Discard the supernatant.

7. Resuspend the cells in $0.3 \mathrm{ml}$ of $0.1 \mathrm{M}$ EDTA, $50 \mathrm{mM}$ Tris-HCl, $\mathrm{pH}$ 8.0, and mix well.

8. Add $0.03 \mathrm{ml}$ of $10 \% \mathrm{SDS}$, mix well and incubate the mixture at $65^{\circ} \mathrm{C}$ for 20 minutes.

9. Add $0.11 \mathrm{ml}$ of $5 \mathrm{M}$ potassium acetate and place the microfuge tube on ice for 60 minutes.

10. Centrifuge in a microfuge at $15000 \mathrm{rpm}$ for 10 minutes.

11. Transfer the supernatant to a fresh microfuge tube and add one volume of $100 \%$ cold ethanol at room temperature. Mix and allow it to sit at room temperature for 5 minutes. Centrifuge in a microfuge at $15000 \mathrm{rpm}$ for 10 minutes. Discard the supernatant.

12. Add $100 \mu 170 \%$ cold ethanol.

13. Centrifuge at $15000 \mathrm{rpm}$ for 5 minutes. Discard the supernatant and air-dry the pellet.

14. Resuspend the pellet in $0.3 \mathrm{ml}$ of distilled water.

15. Add $1 \mu \mathrm{l}$ of a $10 \mathrm{mg} / \mathrm{ml}$ solution of RNase $\mathrm{A}$ and incubate at $37^{\circ} \mathrm{C}$ for 30 minutes. 
16. Add one volume of $100 \%$ cold ethanol. Mix and allow it to sit at temperature for 5 minutes. Centrifuge in a microfuge at $15000 \mathrm{rpm}$ for 10 minutes to harvest the pellet of DNA.

17. Discard the supernatant and add $100 \mu 170 \%$ cold ethanol.

18. Centrifuge at $15000 \mathrm{rpm}$ for 5 minutes. Discard the supernatant and air-dry. Resuspend the pellet of DNA in $100 \mu 1$ of distilled water.

\section{B. Telomeric sequences of pTLUs are amplified by PCR}

\section{PCR Amplification}

1. Prepare a solution ( $49 \mu \mathrm{l}): 5 \mu \mathrm{l}$ of $10 \mathrm{xKOD}$ buffer ( $1.2 \mathrm{mM} \mathrm{MgCl}_{2}$ at the final concentration) Toyobo), $5 \mu \mathrm{l}$ of $2 \mathrm{mM} \mathrm{dNTPs}, 1 \mu \mathrm{l}$

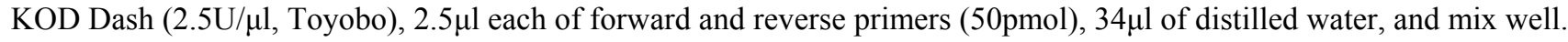

Note: The left plasmid end containing telomeric repeats is amplified using the primers, \#1 (5'CACACACCACACCCACACAC3') and \#2 (5'GAATCAAA GTCTTCATATAC3'). The primer \#1 is designed to contain the nucleotides complementary to a major telomeric motif 5'TGTGTGGGTGTGG3', which was revealed previously (Takata et al. 2000). The primer \#2 is complementary to a part of pTLU (nucleotide positions 276 to 295 inward from the left ITR end, see Fig. 1).

The right plasmid end containing telomeric repeats is amplified using the primers, \#1 and \#3 (5'GGACTTAATGATATACCTAGAG3'). The \#3 primer is designed to be complementary to a part of pTLU (nucleotide positions 471 to 492 inward from the right ITR end, see Fig. 1).

2. Add $1 \mu \mathrm{l}(10 \mathrm{ng})$ of the template DNA (DNA in TE/10) to the PCR solution above. After careful mixing by hand and thermocycling is performed.

3. The PCR amplification ( $50 \mu \mathrm{l}$ in total) is carried out as follows: denaturation at $94^{\circ} \mathrm{C}$ for 30 seconds, annealing at $55^{\circ} \mathrm{C}$ for 2 seconds, extension at $74^{\circ} \mathrm{C}$ for 30 seconds, repeating of 30 cycles, and hold at $4{ }^{\circ} \mathrm{C}$.

4. After amplification, the PCR products are placed into a $1.5 \mathrm{ml}$ microfuge tube.

5. Add $5 \mu \mathrm{l} 3 \mathrm{M}$ sodium acetate (pH 4.8) and $130 \mu \mathrm{l} 100 \%$ cold ethanol, and mix well.

6. Incubate at $-90^{\circ} \mathrm{C}$ for one hour.

7. Centrifuge at $15000 \mathrm{rpm}$ for 10 minutes. Discard the supernatant.

8. Add $100 \mu 170 \%$ cold ethanol.

9. Centrifuge at $15000 \mathrm{rpm}$ for 5 minutes. Discard the supernatant.

10. The DNA pellet is dissolved in $10 \mu \mathrm{l}$ of distilled water (final concentration of ca.30ng/ $\mu \mathrm{l}$ of DNA). 


\section{Telomere-sequencing is analyzed by the chain termination method}

Sequencing is done by the chain termination method using primer \#4 (5'GTATAATAAAATGACTTATAGG3'), which is designed to be complementary to the nucleotides 171-192 inward from each ITR end (see Fig. 1).

The sequencing solution contains the following in a final volume $20 \mu \mathrm{l}: 8 \mu 1$ Terminator premix, ${ }^{\text {a) }}, 3.2 \mathrm{pmol}$ primer $\# 4,3 \mu \mathrm{l}$ (ca.90ng)

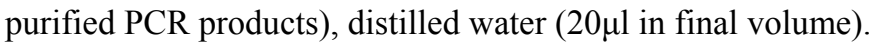

a) Terminator premix: $4 \mu 1$ xSequencing buffer, $1 \mu \mathrm{dNTP}$ mix, $0.5 \mu$ l Dye deoxy terminators, $1 \mu \mathrm{l}$ AmpliTaqFS in $8 \mu \mathrm{l}$ )

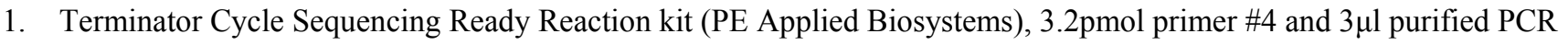
products.

2. Sequence reaction (Dye Terminator Cycle Sequencing): The amplification profile is as follows. Initial denaturation at $96^{\circ} \mathrm{C}$ for $1 \mathrm{~min}$. Denaturation at $96^{\circ} \mathrm{C}$ for $10 \mathrm{sec}$., annealing at $50^{\circ} \mathrm{C}$ for $5 \mathrm{sec}$., and extension at $60^{\circ} \mathrm{C}$ for $4 \mathrm{~min}$. The reaction was repeated 25 cycles. In our experiment, the TAKARA PCR Personal Thermal Cycler (TAKARA Shuzo) was used.

3. PCR products were purified by ethanol precipitation. Transfer the PCR products to a $1.5 \mathrm{ml}$ microfuge tube. Add $2 \mu 13 \mathrm{M}$ $\mathrm{NaOAc}(\mathrm{pH} 4.8)$ and $50 \mu \mathrm{l} 100 \%$ cold ethanol. Incubate on ice for $1 \mathrm{hr}$.

4. Centrifuge for $20 \mathrm{~min}$. at $15,000 \mathrm{rpm}$. Transfer the supernatant. Add $250 \mu 170 \%$ cold ethanol.

5. Centrifuge for $5 \mathrm{~min}$. at $15,000 \mathrm{rpm}$. Transfer the supernatant.

6. Pellet was used for automated sequencer (ABI373S, PE-Applied Biosystems). 